\title{
Formation of Nano Interface by Sliding between Hard Coatings and Metals in MoDTC Contained Oil
}

\author{
Ryo Koike ${ }^{1)^{*}}$, Atsushi Suzuki ${ }^{2)}$, Kazue Kurihara ${ }^{3)}$ and Koshi Adachi ${ }^{4)}$ \\ ${ }^{1)}$ Project F, Toyota Motor East Japan, INC., 1 Chuodaira, Ohira-mura, Kurokawa-gun, Miyagi 981-3609, Japan \\ ${ }^{2)}$ Material Engineering Dept., Aisin Corporation, 2-1 Asahi-machi, Kariya, Aichi 448-8650, Japan \\ ${ }^{3)}$ New Industry Creation Hatchery Center, Tohoku University, 6-6-10 Aoba, Aramaki-aza, Aoba-ku, Sendai, Miyagi 980-8579, Japan \\ ${ }^{4)}$ Department of Mechanical Systems Engineering, Tohoku University, 6-6-01 Aoba, Aramaki-aza, Aoba-ku, Sendai, Miyagi 980-8579, Japan \\ *Corresponding author: Ryo Koike (ryou.koike@toyota-ej.co.jp)
}

Manuscript received 14 September 2021; accepted 20 November 2021; published 15 January 2022

(Translation from the Japanese original: Journal of Japanese Society of Tribologists, 64, 8, 2019, 504-512, JAST Best Paper Award Winner in 2020)

\begin{abstract}
The viscosity of motor oil gets lower in order to decrease resistance at region of the fluid lubrication. On the other hands, this causes increasing of friction at the boundary lubrication region. For this reason, it is required to use a friction modifier to reduce the boundary friction. MoDTC is especially used as friction modifier. Although the decomposition mechanism of MoDTC has been presumed, it is considered only in the case of metal, not hard coatings. So, it is required to understand the effects of hard coatings to friction in motor oils. We tried to clarify the surface and tribofilm changes depending on the kinds of hard coatings by SEM-EDX, TEM and so on. As a result of experiment of hard coatings against metal, we clarified the process as follows when friction of CrN reduces. In the early stage of friction, $\mathrm{Fe}$ of the opposite metal transfers to $\mathrm{CrN}$. $\mathrm{Mo}_{2} \mathrm{~S}_{2} \mathrm{O}_{2}$ intermediate product which is formed by MoDTC decomposition is formed on $\mathrm{CrN}$ divided into Fe oxide and Mo sulfide. At this time, crystal orientation between Fe oxide and $\mathrm{CrN}$ is matching because the lattice constant of Fe oxide is twice that of $\mathrm{CrN}$. These results show that the crystal structure of hard coatings is important for formation of stable interface. And this newly knowledge is necessary to achieve low friction for systems using hard coatings.
\end{abstract}

\section{Keywords}

boundary lubrication, additive, molybdenum disulfide, molybdenum dithiocarbamate, tribofilm, tribochemistry, interface, hard coating, transfer, transmission electron microscopy

\section{Introduction}

In the recent years, there has been an increasing demand for high-efficiency automobile fuel; friction reduction by lowering the viscosity of engine oil has been considered an effective method to produce high-efficiency automobile fuel [1]. However, several trade-offs are associated with lowering the viscosity of engine oil; these include increase in oil consumption and the possibility of seizures due to an increase in the boundary friction ratio under low-speed sliding conditions [2]. The friction between the cylinder and piston ring could be reduced through the oil film formation effect by Febased thermal spraying on the bore side [3, 4]; however, cast iron wrapping liners are still widely used. The top ring and second ring often comprise $\mathrm{Cr}$ nitride films fabricated via arc ion plating (AIP); however, several attempts have been made to reduce fluid loss by using the diamond-like carbon (DLC) films of ta-C instead of $\mathrm{Cr}$ nitride films and by narrowing the films. Both of these technologies can be employed to achieve low friction and seizure resistance; however, it is also important to design the interface while considering the combination of the lubricating oil and material.

One method of reducing the friction in the boundary lubrication region within the lubricating oil is the addition of friction modifiers, such as molybdenum dithiocarbamate (MoDTC), to the lubricating oil. It is assumed that MoDTC is decomposed by the frictional energy, which produces a lowfriction $\mathrm{MoS}_{2}$ as a tribofilm, thus achieving a low friction [57]. In addition, it has been reported that, during the MoDTC decomposition process, after MoDTC decomposes into the $\mathrm{N}$-containing organic part and molybdenum acid sulfide $\mathrm{MoO}_{2-x} \mathrm{~S}_{x}$, the obtained intermediate takes oxygen externally and decomposes to $\mathrm{MoO}_{3}$ and $\mathrm{MoS}_{2}$ [8-11]; furthermore, after the initial formation of sulfide $\mathrm{MoS}_{\mathrm{x}}$ from shearing, multiple cases are observed depending on various conditions, such as temperature and additive concentration: first, where $\mathrm{FeMoO}_{3}$ 
is formed and friction does not decrease, and second, where $\mathrm{MoS}_{2}$ is formed and friction decreases [12]. Rai et al. focused on the peak shift of Raman spectroscopy in the friction process and reported that the layered structure of the formed $\mathrm{MoS}_{2}$ contributed to a decrease in the friction [13]; thus, forming $\mathrm{MoS}_{2}$ with a more effective structure is the key to achieving lower friction.

Accordingly, advances in $\mathrm{MoS}_{2}$ formation mechanisms using MoDTC are being made; however, this model assumes the existence of an active metal formation surface, and thus does not apply to hard coatings, which are conventionally used for piston rings. Therefore, the $\mathrm{MoS}_{2}$ formation process must be further investigated with regard to the friction between the metals and hard coatings such as $\mathrm{CrN}$ in the engine oil.

Therefore, this study investigates the running-in process due to the friction in the MoDTC-contained oil while using hard coatings such as $\mathrm{CrN}$, which are primarily used in the piston rings, to clarify the tribofilm formation process for lowering the friction. Another objective of this paper is to clarify the effect of hard coatings on the formation of the low-friction interface to show guidelines for hard coatings that are needed for lowering friction.

\section{Experimental method}

2.1 Experimental devices and conditions

In the friction tests, a ball-on-disk apparatus was employed (Fig. 1). The test was performed by immersing the contact part in an oil, which was placed in a constant temperature bath to stabilize the temperature of the lubricating oil and reduce the effect of the supply amount. The immersion process caused resistance to oil stirring; therefore, a correction value $(0.01$ $\mathrm{N}$ under test conditions) was measured in advance without subtracting the load to calculate the frictional force.

The friction conditions were kept constant at a slip speed of $0.5 \mathrm{~m} / \mathrm{s}$, load of $10 \mathrm{~N}$, and lubricating oil temperature of $80^{\circ} \mathrm{C}$. The surface conditions in the running-in process were confirmed using multiple ball and disk specimens; the test was stopped during the friction process to observe and analyze the ball and disk wear scars.

\subsection{Specimens and lubricating oil}

The ball specimens were composed of a stainless steel (SUS440C) with a hardness of HRC50 and diameter of $8 \mathrm{~mm}$. Three types of hard coatings, $\mathrm{CrN}, \mathrm{Cr}_{2} \mathrm{~N}$, and hard $\mathrm{Cr}$ plating (Table 1), were applied to the ball side to study the piston ring

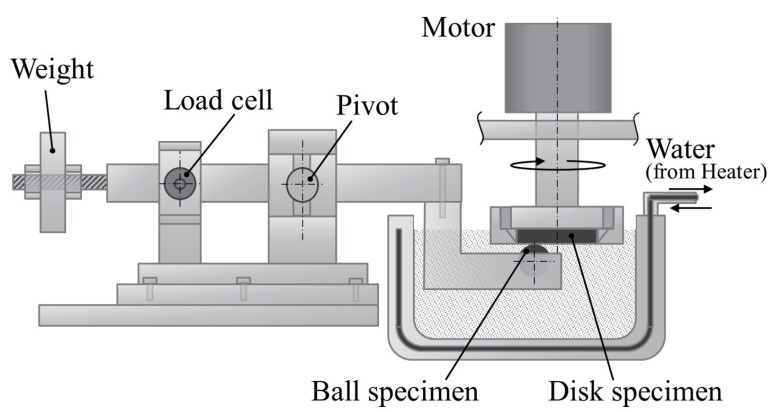

Fig. 1 Schematic drawing of ball-on-disk friction apparatus; reproduced with permission from [22] Copyright (2019) Japanese Society of Tribologists
Table 1 Characteristic of hard coatings for ball specimen; reproduced with permission from [22] Copyright (2019) Japanese Society of Tribologists

\begin{tabular}{c|c|c|c}
\hline & $\mathrm{CrN}$ & $\mathrm{Cr}_{2} \mathrm{~N}$ & Cr plating \\
\hline Substrate & SUS440C & SUS440C & SUS440C \\
\hline $\begin{array}{c}\text { Forming } \\
\text { method }\end{array}$ & $\begin{array}{c}\text { Arc ion } \\
\text { plating(AIP) }\end{array}$ & $\begin{array}{c}\text { Arc ion } \\
\text { plating(AIP) }\end{array}$ & $\begin{array}{c}\text { Electrolytic } \\
\text { plating }\end{array}$ \\
\hline Hardness & $1324 \mathrm{Hv}$ & $1447 \mathrm{Hv}$ & $858 \mathrm{Hv}$ \\
\hline Thickness & $3 \mu \mathrm{m}$ & $3 \mu \mathrm{m}$ & $20 \mu \mathrm{m}$ \\
\hline
\end{tabular}

phenomenon. The $\mathrm{CrN}$ and $\mathrm{Cr}_{2} \mathrm{~N}$ coatings with a film thickness of $3 \mu \mathrm{m}$ were fabricated using the arc ion plating method. The hard $\mathrm{Cr}$ plating had a film thickness of $20 \mu \mathrm{m}$. Furthermore, the disk substrates were composed of either a bearing steel (SUJ2) or $\mathrm{CrN}$ formed on SUJ2 under the same conditions as that of the ball specimens. The disk substrates had a diameter of 30 $\mathrm{mm}$ and thickness of $4 \mathrm{~mm}$, and each of them were ground to a roughness of $R a 0.18 \pm 0.05$. The Vickers hardness of the ball specimens were measured with a micro-Vickers hardness tester (Shimadzu Corp. HMV-G), and the measurements were performed with a measured load of $0.1 \mathrm{~N}$ and retention time of $10 \mathrm{~s}$. Deposited $\mathrm{CrN}$ and $\mathrm{Cr}_{2} \mathrm{~N}$ were subjected to X-ray diffraction (XRD) using a completely automatic horizontal multi-purpose X-ray diffractometer (Rigaku SmartLab) to confirm the crystal structure of the surface.

In the lubricating oil, Poly- $\alpha$-olefin (PAO8), which exhibited a kinematic viscosity of $48 \mathrm{cSt}$ at $40^{\circ} \mathrm{C}$ and $8 \mathrm{cSt}$ at $100^{\circ} \mathrm{C}$, was used as a base oil, with an addition of MoDTC (220 ppm for Mo) and calcium sulfonate (120 ppm for $\mathrm{Ca}$; henceforth abbreviated as "MoDTC-contained oil" in the text and "Mo+Ca / PAO8" in the figures).

\subsection{Surface observations and analysis method}

The surface shape was determined using a nano-search microscope (Olympus LSM / Shimadzu Corp; AFM SFT3500), which integrated a scanning laser microscope and scanning probe microscope, to observe the ball surface.

During the surface chemical analyses of the disk and ball wear scars during the test, an energy-dispersed X-ray (EDX) in a scanning electron microscope (Hitachi High-Tech Corp. SEM SU8020) was employed to analyze the composition. The EDX analyses superimposed the $\mathrm{S} \mathrm{K} \alpha(2.307 \mathrm{keV})$ and $\mathrm{Mo} \mathrm{L} \alpha(2.293$ $\mathrm{keV}) \mathrm{X}$-rays; therefore, the Mo K $\alpha$ X-ray $(17.441 \mathrm{eV})$ was used for the Mo concentration. $\mathrm{MoS}_{2}$ was analyzed using a confocal laser Raman spectrometer (Tokyo Instruments Nanofinder) on the wear scar, and the spectrum was measured under the conditions shown in Table 2. We used disk specimens for Raman spectroscopy analysis that had a corrugated streak with a depth of $10 \mu \mathrm{m}$ and width of $200 \mu \mathrm{m}$ applied in one direction,

Table 2 Measurement conditions for Raman; reproduced with permission from [22] Copyright (2019) Japanese Society of Tribologists

\begin{tabular}{c|c|c|c}
\hline Instrument & Nanofinder & Lazar power & $14 \mathrm{~mW}$ \\
\hline $\begin{array}{c}\text { Excitation } \\
\text { wavelength }\end{array}$ & $532 \mathrm{~nm}$ & Grating & $1800 \mathrm{G} / \mathrm{mm}$ \\
\hline Exposure time & $1 \mathrm{sec}$ & Pinhole & $90 \mu \mathrm{m}$ \\
\hline Accumulations & 600 cycles & Objective & $\mathrm{x} 20$ \\
\hline
\end{tabular}


and subsequently analyzed the plateau part formed by the wear to investigate the presence of $\mathrm{MoS}_{2}$ on the contact surface of the disk and ball specimens.

The sample for cross-sectional observation of tribofilm formed after sliding was cut out from the ball wear scars in a direction parallel to the sliding direction using a dual type focus ion beam (FIB) processing device (FIB Versa3D Dual Beam). In other words, the obtained cross-sectional image was a crosssection along the sliding direction. This sample was used to conduct electron backscatter diffraction (EBSD) in SEM to analyze the crystalline direction of the hard coating.

Furthermore, the tribofilm cross-section was subjected to transmission electron microscopy (TEM) and scanning transmission electron microscopy (STEM) observations using a spherical aberration-correct scanning transmission electron microscope (JEOL Ltd. Cs-corrected STEM JEM-ARM200F), as well as electron energy loss spectroscopy (EELS) and energydispersed X-ray (EDX) analyses to identify its chemical composition. Line analysis by EDX and EELS in TEM was done at a pitch of $4 \mathrm{~nm}$.

\section{Experimental results}

\subsection{Cr nitride film structure}

Figure 2(a) shows the SEM image of the CrN-applied ball specimen before friction was applied. Figure 2(b) presents the cross-sectional SEM image of the sampling area shown in Fig. 2(a). Finally, Fig. 2(c) shows the crystalline direction mapping by EBSD. This crystalline direction mapping was the crystalline direction distribution facing the A1 direction (i.e., the film thickness direction) in the figure. Furthermore, Fig. 3 shows the X-ray diffraction spectra of $\mathrm{CrN}$ and $\mathrm{Cr}_{2} \mathrm{~N}$ applied to the ball. The results showed that the $\mathrm{CrN}$ film grew in the (200) direction near the base material; however, there existed a random crystalline direction in the (111) and (311) planes on the surface, and $\mathrm{Cr}_{2} \mathrm{~N}$ was a film with various crystal planes.

\subsection{Effect of hard coating species on the friction properties}

Figure 4 shows the typical friction properties of the $\mathrm{CrN}$ deposited ball and SUJ2 disk specimens in the base oil (PAO8)

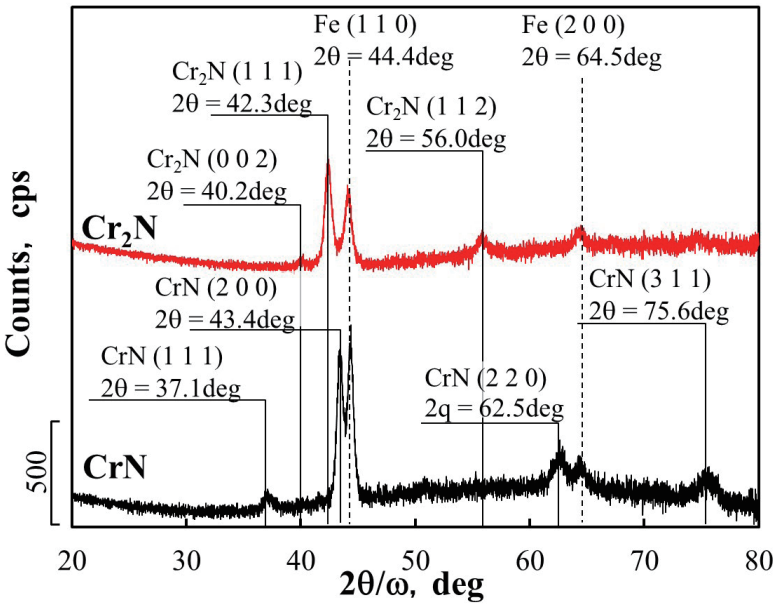

Fig. 3 X-ray diffraction spectrum of $\mathrm{CrN}$ ball and $\mathrm{Cr}_{2} \mathrm{~N}$ ball by $\theta-2 \theta$ method; reproduced with permission from [22] Copyright (2019) Japanese Society of Tribologists

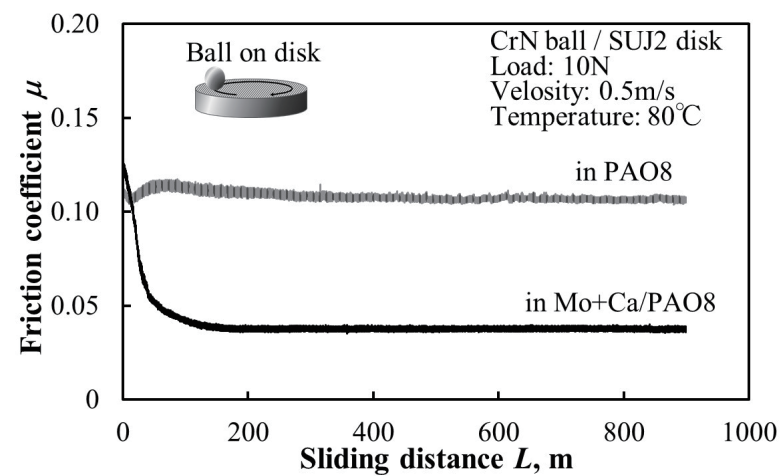

Fig. 4 Friction properties of $\mathrm{CrN}$ ball sliding against SUJ2 disk with PAO8 and MoDTC contained oil; reproduced with permission from [22] Copyright (2019) Japanese Society of Tribologists

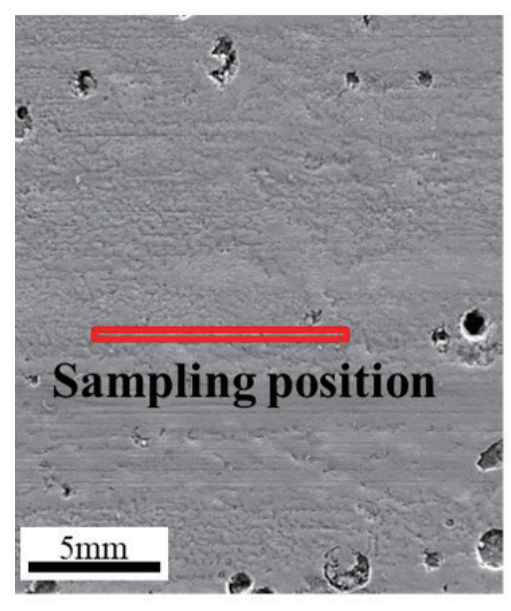

(a)

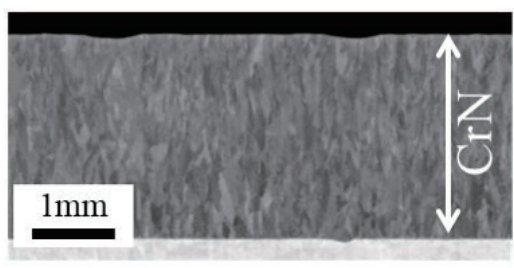

(b)

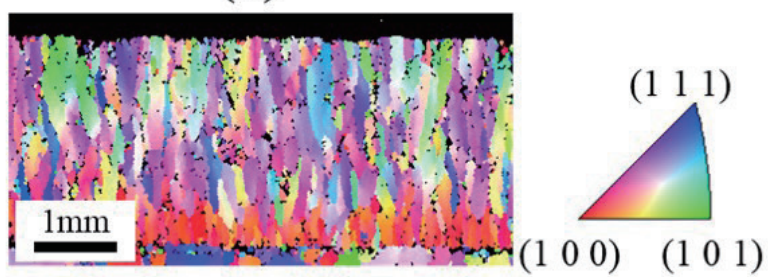

(c)

Fig. 2 Surface and structure of CrN coated ball, (a) surface SEM image, (b) cross section SEM image of sampling position indicated on (a), (c) crystalline direction mapping from A1 direction (IPF image of EBSD); reproduced with permission from [22] Copyright (2019) Japanese Society of Tribologists 
and MoDTC-contained oil. The friction decreased from the initial stage and stabilized only in the MoDTC-contained oil; thus, it could be inferred that the friction coefficient decreased as a result of the formation of the tribofilm by MoDTC. Figure 5 shows the typical friction properties when the three types of hard coating (Table 1) slid against the SUJ2 disk in the MoDTCcontained oil. The results of sliding with the $\mathrm{CrN}$ disk and $\mathrm{CrN}$ ball are also shown in Fig. 5 for reference. The friction decreased from the initial stage and the friction coefficient stabilized when $\mathrm{CrN}$ - and hard Cr-plating-applied ball specimens were applied and slid with the SUJ2 disk specimen. However, the friction did not decrease in $\mathrm{Cr}_{2} \mathrm{~N}$ despite being the same $\mathrm{Cr}$ nitride as $\mathrm{CrN}$. Furthermore, the friction did not decrease even when the $\mathrm{CrN}$ ball and $\mathrm{CrN}$ disk specimens were slid, thus indicating that the presence of Fe as a mating material is important for hard coating.

\subsection{Transfer of Fe to ball wear scars}

The results shown in Section 3.2 suggest that the friction of the hard coating requires the presence of $\mathrm{Fe}$ in the mating material SUJ2. These factors were analyzed using stopping tests when a sliding distance or friction coefficient reached a certain value when SUJ2 was employed as a disk material (example shown in Fig. 6), creating samples with different sliding distances, and analyzing the chemical composition of the wear

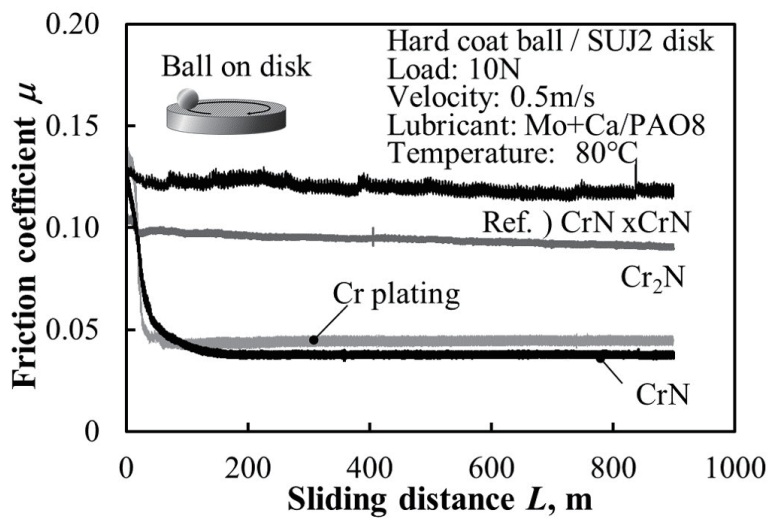

Fig. 5 Friction properties of various hard coatings sliding against SUJ2 disk in MoDTC contained oil; reproduced with permission from [22] Copyright (2019) Japanese Society of Tribologists

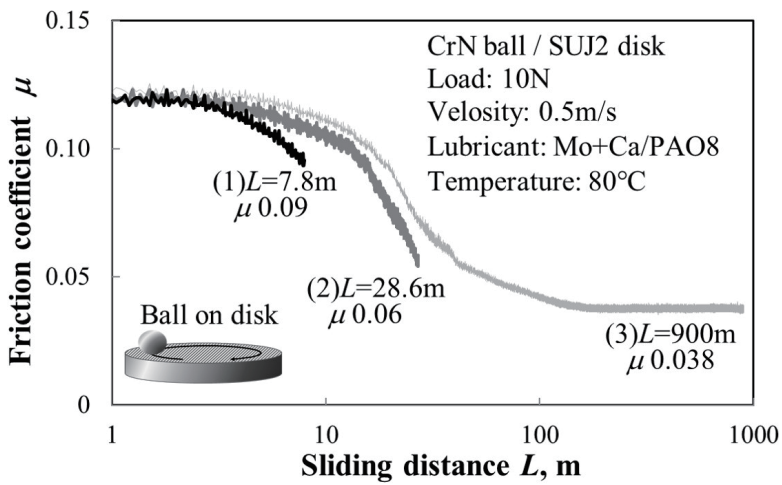

Fig. 6 Example of friction test of $\mathrm{CrN}$ sliding against SUJ2 disk in MoDTC contained oil; reproduced with permission from [22] Copyright (2019) Japanese Society of Tribologists scars. Figure 7 shows the changes in semi-quantitative values of $\mathrm{Fe}, \mathrm{Mo}$, and $\mathrm{O}$ evaluated using EDX on the $\mathrm{CrN}$ ball wear scars in this friction process. Fe was not detected outside these wear scars, and it was determined that the Fe present in the ball wear scars were transferred from the disk material SUJ2. Although the quantification accuracy of EDX is low, Fe was abundantly present in the early friction stages, and a gradually decreasing tendency could be seen in the process of decreasing friction. Meanwhile, the Mo from MoDTC showed a slightly increasing tendency, suggesting that the Fe transferred in the early friction stages contributed to the reaction of MoDTC. Furthermore, Fig. 8 shows the influence of the ball's hard coating on the changes in the concentration of Fe transferred to the ball wear scars. Fe was present on the ball wear scars of $\mathrm{CrN}$ and $\mathrm{Cr}_{2} \mathrm{~N}$, and a gradually decreasing tendency could be seen. Furthermore, Fe had a gradually increasing tendency in the hard $\mathrm{Cr}$ plating.

\subsection{Effect of hard coating type on $\mathrm{MoS}_{2}$ formation}

The results presented in Sections 3.2 and 3.3 indicate that the transfer of Fe from the mating material plays an important role in the formation of $\mathrm{MoS}_{2}$ from MoDTC decomposition in systems using a hard coating that cannot generate an active metallographic surface. Meanwhile, $\mathrm{CrN}$ and $\mathrm{Cr}_{2} \mathrm{~N}$ both have a process of $\mathrm{Fe}$ transfer but have completely different friction properties, as shown in Fig. 5. Therefore, Fe transfer is a necessary condition for $\mathrm{MoS}_{2}$ formation and cannot be said to be a sufficient condition. Figure 9 shows the Raman spectra

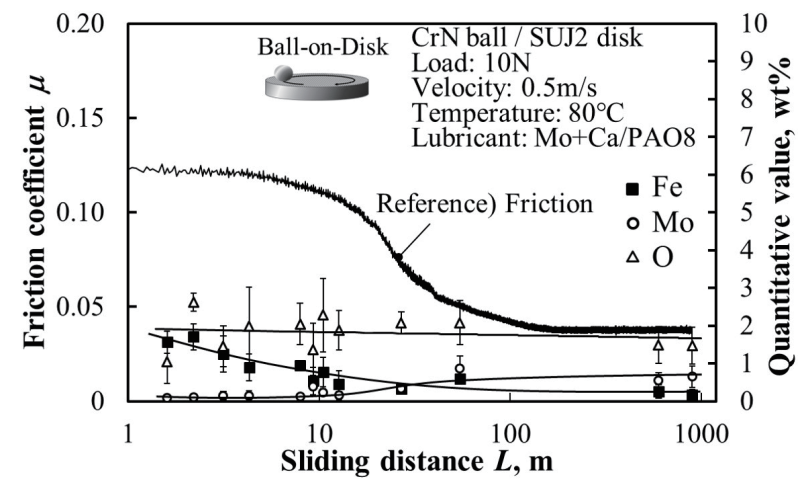

Fig. 7 Changes of chemical composition of $\mathrm{CrN}$ ball scar; reproduced with permission from [22] Copyright (2019) Japanese Society of Tribologists

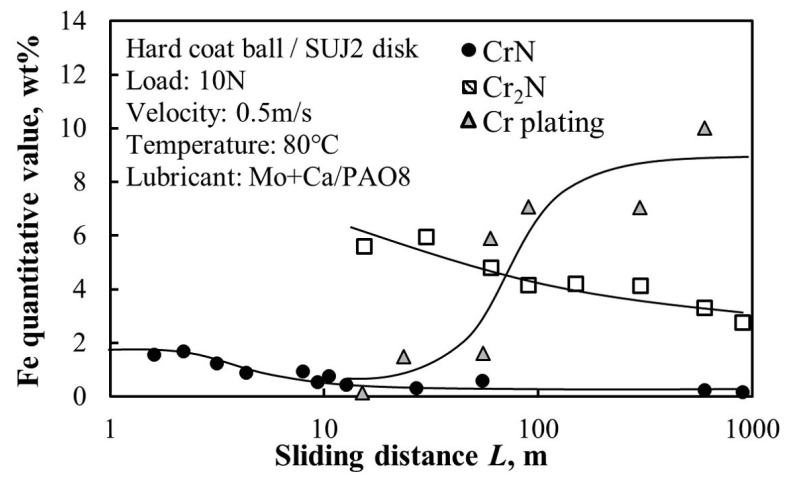

Fig. 8 Changes of Fe concentration on various hard coated balls; reproduced with permission from [22] Copyright (2019) Japanese Society of Tribologists 


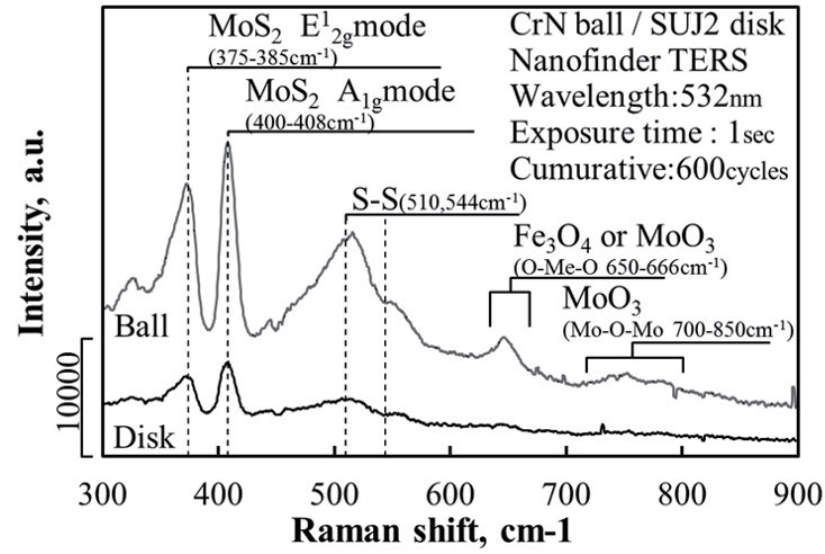

(a)

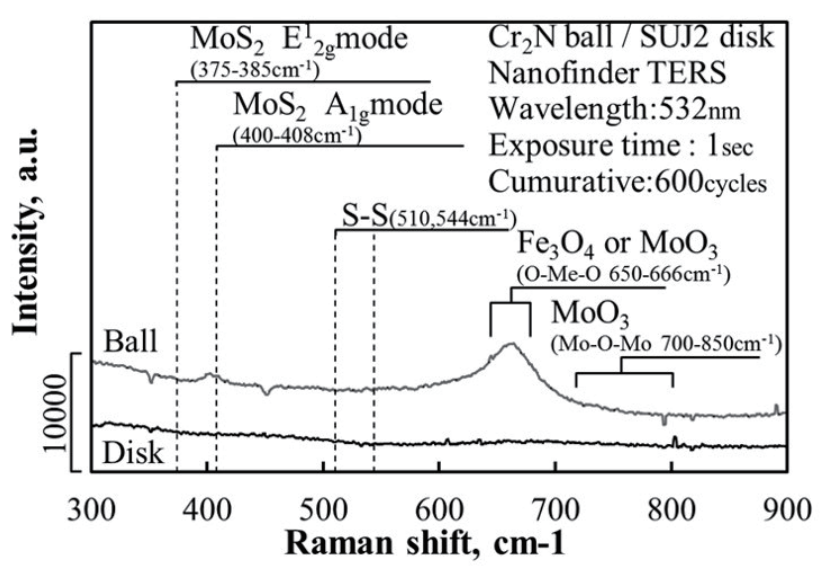

(b)

Fig. 9 Raman spectra around $\mathrm{MoS}_{2}$ peak, (a) $\mathrm{CrN}$ ball (b) $\mathrm{Cr}_{2} \mathrm{~N}$ ball; reproduced with permission from [22] Copyright (2019) Japanese Society of Tribologists

of wear scars in $\mathrm{CrN}$ ball-SUJ2 disk and $\mathrm{Cr}_{2} \mathrm{~N}$ ball-SUJ2 disk specimen combinations. Differences in the Raman vibration direction of Mo and $\mathrm{S}$ have been reported to cause the existence of two $\mathrm{MoS}_{2}$ peaks at the $\mathrm{E}_{2 \mathrm{~g}}^{1}$ mode $\left(375-385 \mathrm{~cm}^{-1}\right)$ and $\mathrm{A}_{\mathrm{g}}^{1}$ mode $\left(400-408 \mathrm{~cm}^{-1}\right)$, as well as several peaks between $650-850 \mathrm{~cm}^{-1}$ due to Fe and Mo oxides [11, 13-15]. $\mathrm{MoS}_{2}$ peaks were confirmed from both the ball and disk specimens when the $\mathrm{CrN}$ ball was used (Fig. 9(a)), while peaks thought to be $\mathrm{Fe}_{3} \mathrm{O}_{4}$ or $\mathrm{MoO}_{3}$ were mainly detected when $\mathrm{Cr}_{2} \mathrm{~N}$ was used (Fig. 9(b)). These results signified that the low-friction-inducing $\mathrm{MoS}_{2}$ was formed only when $\mathrm{CrN}$ was used. Meanwhile, $\mathrm{MoS}_{2}$ was not present when $\mathrm{Cr}_{2} \mathrm{~N}$ was used, but $\mathrm{MoO}_{3}$ was present instead, and it was thought that $\mathrm{MoS}_{2}$ could not be fixed on the wear scars despite MoDTC decomposition.

\subsection{Fe nano-interface formation in tribofilm}

During the friction process between SUJ2 and the CrN or $\mathrm{Cr}_{2} \mathrm{~N}$ coating, Fe was initially transferred and gradually decreased, but different coating types resulted in different reaction products $\left(\mathrm{MoS}_{2}\right.$ and $\left.\mathrm{MoO}_{3}\right)$ formed as a result of MoDTC decomposition. Figures 10 and 11 show the cross-sectional TEM image of the $\mathrm{Cr}_{2} \mathrm{~N}$ and $\mathrm{CrN}$-applied ball wear scars after friction stabilized and the EDX mapping of each element in the rectangular region, respectively. The $\mathrm{Cr}_{2} \mathrm{~N}$-applied ball wear scars had an amorphous tribofilm containing $\mathrm{Fe}, \mathrm{Mo}$, and $\mathrm{O}$. $\mathrm{S}$ was not present, and thus $\mathrm{MoS}_{2}$ did not form; and this was consistent with the above-mentioned friction properties and Raman spectra results. Meanwhile, the $\mathrm{CrN}$-applied ball wear scars had abundant Mo and S on the surface layer side and exhibited a layered structure; therefore, based on the results in Fig. 9, it could be said that the layered structure was $\mathrm{MoS}_{2}$. EDX mapping (Fig. 11(b)) also indicated the formation of an interface with Fe detected between $\mathrm{MoS}_{2}$ and the parent material CrN.

Figure 12 shows the (a) cross-sectional bright field image of the CrN-applied ball wear scar obtained using highresolution STEM, (b) dark field image with only the inside of the rectangular frame enlarged, (c) $\mathrm{Fe}_{3} \mathrm{O}_{4}$ atomic arrangement model, and (d) diffraction pattern for determining the crystal structure and crystalline direction of the interface containing Fe. The interface containing Fe was confirmed using the atomic

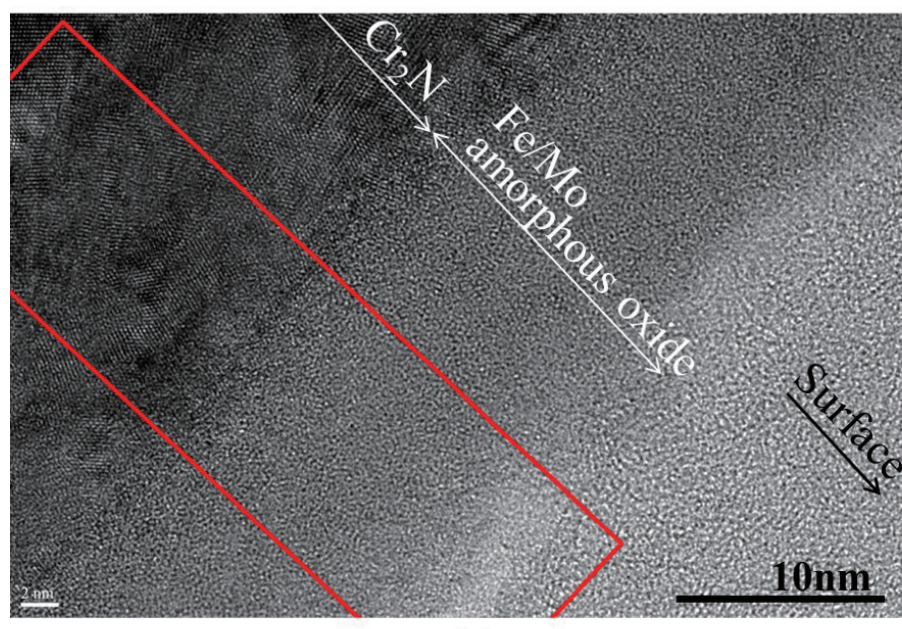

(a)

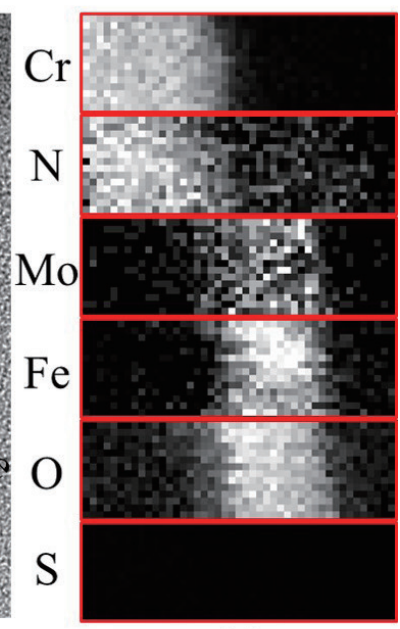

(b)

Fig. 10 Cross section image of reaction film on $\mathrm{Cr}_{2} \mathrm{~N}$ sliding against SUJ2, (a) TEM bright field image, (b) element mapping by EDX at square area in (a); reproduced with permission from [22] Copyright (2019) Japanese Society of Tribologists 


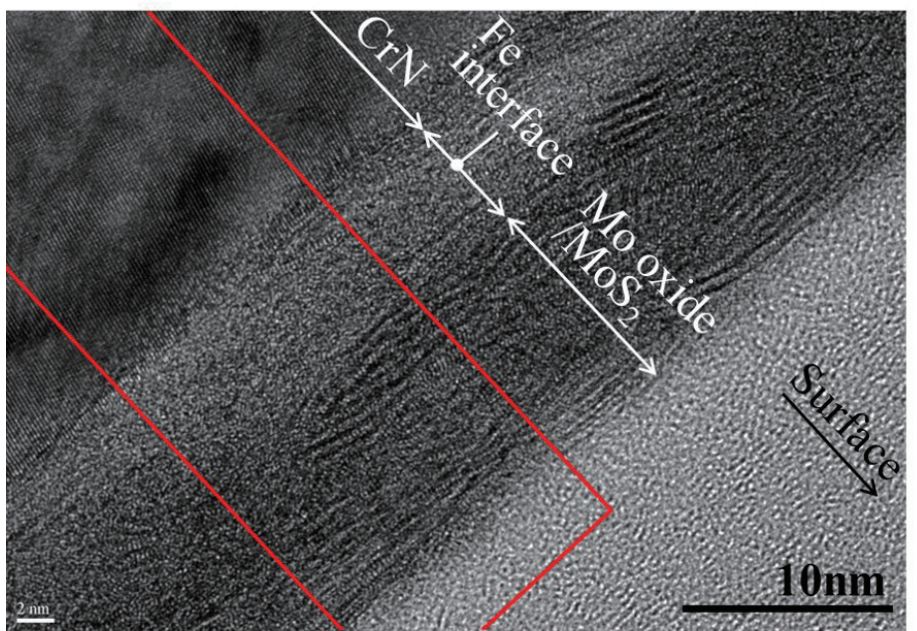

(a)

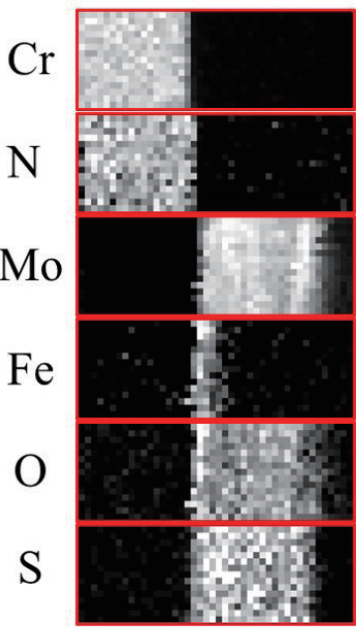

(b)

Fig. 11 Cross section image of reaction film on CrN sliding against SUJ2, (a) TEM bright field image, (b) element mapping by EDX at square area in (a); reproduced with permission from [22] Copyright (2019) Japanese Society of Tribologists

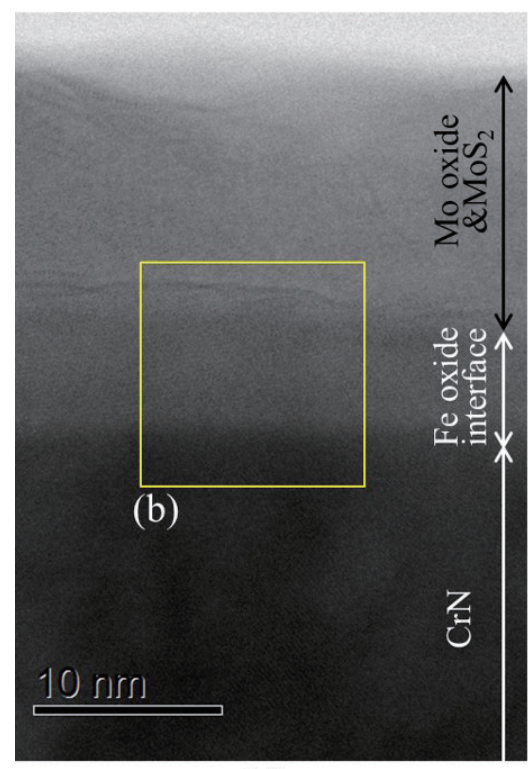

(a)

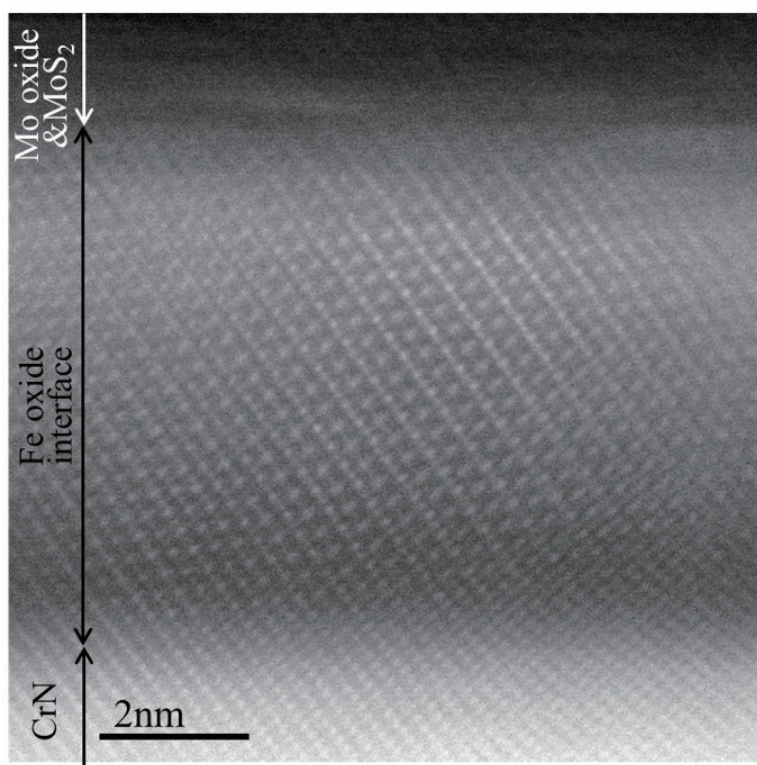

(b)

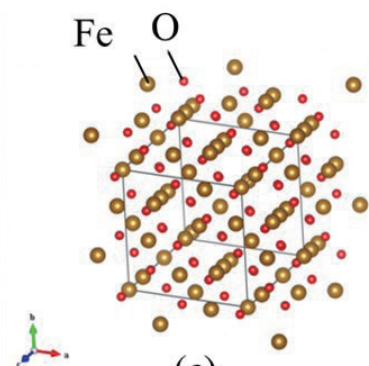

(c)

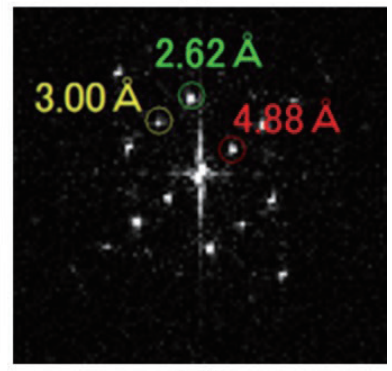

(d)

Fig. 12 Cross section detail image of nano interface on CrN sliding against SUJ2, (a) STEM bright filed image of tribo-film, (b) annular dark field image of Fe interface, (c) simulated crystal structure of $\mathrm{Fe}_{3} \mathrm{O}_{4}$, (d) diffraction pattern at Fe interface; reproduced with permission from [22] Copyright (2019) Japanese Society of Tribologists

image, and it could be inferred from the (c) $\mathrm{Fe}_{3} \mathrm{O}_{4}$ atomic arrangement model that $\mathrm{Fe}_{3} \mathrm{O}_{4}$ was formed in the $\mathrm{CrN}-\mathrm{MoS}_{2}$ interface. It can also be seen that the $\mathrm{Fe}_{3} \mathrm{O}_{4}$ interface had the same crystal orientation as the base material $\mathrm{CrN}$. Despite the transfer of $\mathrm{Fe}$ from the mating material during the friction process, the $\mathrm{CrN}$ crystals matched with the $\mathrm{Fe}_{3} \mathrm{O}_{4}$ crystals, e.g., in terms of the epitaxial growth. Therefore, it could be inferred that Fe crystallized after its transfer during the reaction process with MoDTC (i.e., matched with the underlying CrN by oxidation after transfer). It is speculated that stable friction properties could be attributed to the presence of the $\mathrm{Fe}_{3} \mathrm{O}_{4}$ interface, which was self-formed at the $\mathrm{CrN}-\mathrm{MoS}_{2}$ interface and consistent with such a base material.

\section{Discussion}

4.1 Crystal matching of $\mathrm{Fe}_{3} \mathrm{O}_{4}$ present at friction interface

The occurrence of the crystal matching with $\mathrm{Fe}_{3} \mathrm{O}_{4}$, shown in Fig. 12, in $\mathrm{CrN}$ and not in $\mathrm{Cr}_{2} \mathrm{~N}$ can be explained as follows. $\mathrm{Fe}_{3} \mathrm{O}_{4}$ is generally a spinel-type cubic system with a lattice constant of $0.8386 \mathrm{~nm}$ [16]. CrN is a NaCl-type cubic crystal with a lattice constant of $0.4143 \mathrm{~nm}$ [17]. In other words, both belong to the same cubic system as shown in Fig. 13, and both have a lattice constant of $\mathrm{Fe}_{3} \mathrm{O}_{4}$ that is approximately twice that of $\mathrm{CrN}$ (lattice constant mismatch rate of $1 \%$ ). Using semiconductor materials such as $\mathrm{SiGe}$ as an example, a lattice mismatch rate of $1 \%$ would result in an epitaxial growth-caused critical film 


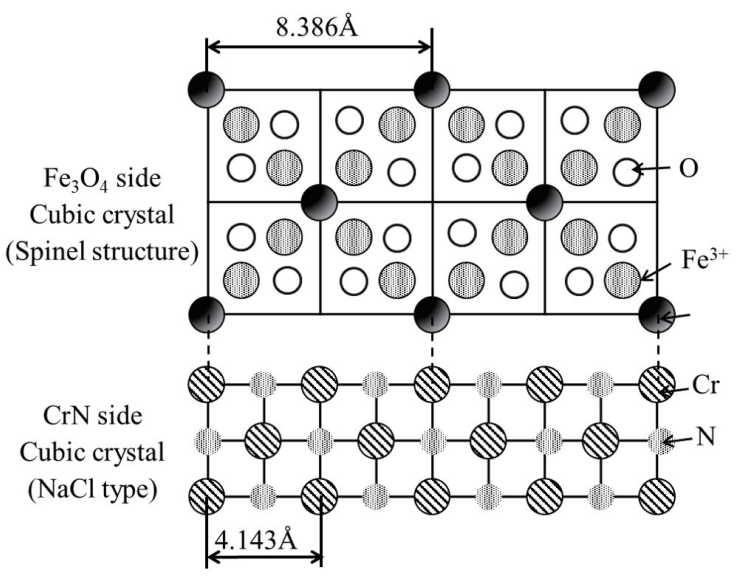

Fig. 13 Schematic image of crystal matching state between $\mathrm{CrN}\left(\mathrm{NaCl}\right.$ cubic crystal) and $\mathrm{Fe}_{3} \mathrm{O}_{4}$ (spinel structure cubic crystal); reproduced with permission from [22] Copyright (2019) Japanese Society of Tribologists

thickness of $50-100 \mathrm{~nm}$ [18]; sufficient matching as a crystal would be obtained if an Fe interface of approximately $5 \mathrm{~nm}$ was present, as observed in Fig. 12. Meanwhile, $\mathrm{Cr}_{2} \mathrm{~N}$ generally has a hexagonal structure [19], and thus it could be inferred that the transferred Fe does not lead to stable interface formation. Thus, the phenomenon of Fe forming a dense oxide interface is based on the essential conditions of whether the crystal structures of the Fe oxide and parent material are the same and whether the lattice constant is an integral multiple.

\subsection{Necessity of Fe oxide interface}

Grossiord et al. reported that the formation of Mo oxides and $\mathrm{MoS}_{2}$ occurred after intermediate products containing $\mathrm{Mo}, \mathrm{S}$, and $\mathrm{O}$ were formed during the MoDTC decomposition process [10]. It is also known that $\mathrm{Cr}$ oxides were present between the tribofilm and base material during friction between metals, especially on materials containing $\mathrm{Cr}$ [20]. In other words, it can be inferred that forming oxides on the tribofilm base material is the key to forming the sulfide $\mathrm{MoS}_{2}$ on the tribofilm surface layer in order to form $\mathrm{MoS}_{2}$ from intermediate products in the MoDTC decomposition process. This indicates that a crystallographically stable oxide of Fe transferred from the mating material on the base material contributes to the formation of $\mathrm{MoS}_{2}$ on the surface layer side in hard coatings that have no reactivity with the film itself. Therefore, hard coating crystallinity can be said to play an important role for stable and low friction.

\subsection{Effect of hard coating species on reaction process}

As shown in Fig. 5, both $\mathrm{CrN}$ and hard $\mathrm{Cr}$ plating rapidly decrease friction and stabilize after the start of the test. However, as shown in Fig. 8, the changes in Fe concentration on the wear scars differ between the two, and based on this, the running-in process could be characterized as follows (Fig. 14).

In the processes involving the hard Cr plating, which forms the $\mathrm{Cr}$ oxide, the plating itself reacts to form the tribofilm, which has oxides at the interface [20], and the $\mathrm{MoS}_{2}$-containing tribofilm repeats the formation and peeling processes to stabilize friction [21]. Meanwhile, in the process involving $\mathrm{CrN}$, Fe transfers from the mating material, reacts with MoDTC, and reduces, thereby forming a nano-interface like that shown in Fig. 12 and generating $\mathrm{MoS}_{2}$. As shown in Figs. 2 and 3, $\mathrm{CrN}$ is a heterogeneous material with various crystalline orientations, and thus nano-interface formation does not always occur over the entire friction surface. In other words, the tribofilm peeling and Fe transfer from the mating material occur simultaneously; reactions with MoDTC in the friction surface also occur. These are thought to maintain low friction. $\mathrm{Cr}_{2} \mathrm{~N}$ involves the transfer of Fe but not the formation of $\mathrm{MoS}_{2}$-containing tribofilm, and thus it can be said that crystallinity for oxide formation from $\mathrm{Fe}$ transferred from the mating material is an important factor for stable $\mathrm{MoS}_{2}$ formation.

\section{Conclusions}

The following conclusions were drawn regarding the expression of low friction in a sliding system using hard coatings in MoDTC-contained oil.

(1) In the running-in process in the initial sliding period, Fe transfer from the mating material is a necessary condition for forming tribofilms containing $\mathrm{MoS}_{2}$ in order to exhibit low friction in nitride films such as $\mathrm{CrN}$, whose hard coating is not reactive itself.

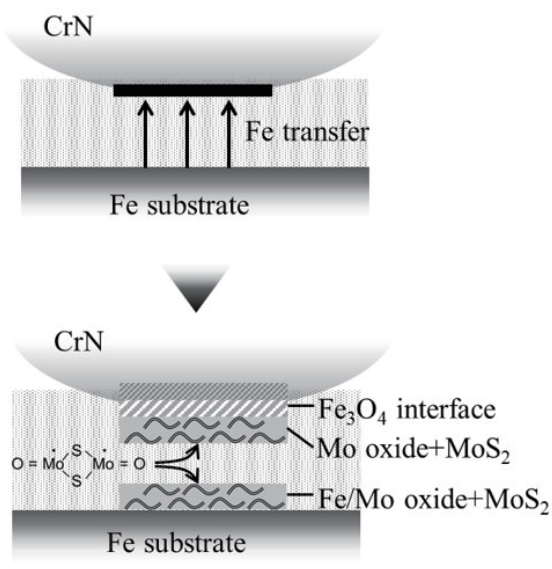

(a) $\mathrm{CrN}$
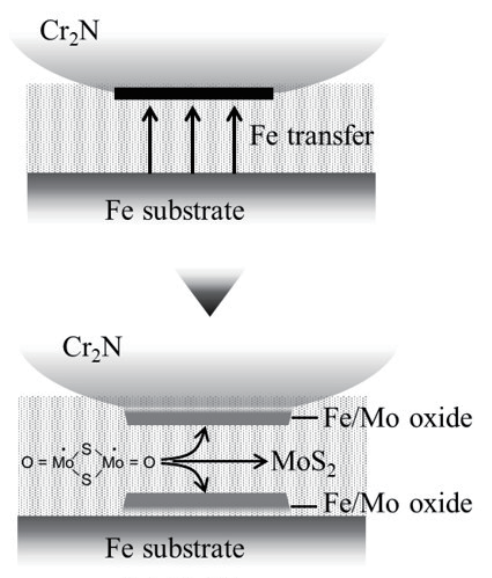

(b) $\mathrm{Cr}_{2} \mathrm{~N}$

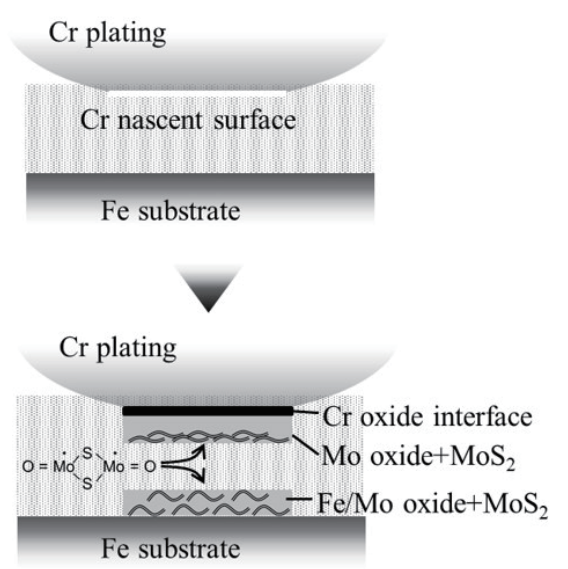

(c) Cr plating

Fig. 14 Schematic image of tribo-film forming process, (a) $\mathrm{CrN}$, (b) $\mathrm{Cr}_{2} \mathrm{~N}$, (c) Cr plating; reproduced with permission from [22] Copyright (2019) Japanese Society of Tribologists 
(2) A tribofilm forming $\mathrm{MoS}_{2}$ on the outermost layer requires the formation of a nano-interface of dense Fe oxides, which is formed as a result of the similarity relation in which the lattice constants of the base material of the hard coating and the Fe oxide crystal are integer multiples.

(3) Fe transferred to $\mathrm{CrN}$ during sliding between $\mathrm{CrN}$ and SUJ2 contributes to reactions with MoDTC, and thus continuous tribofilm peeling and Fe transfer are required to maintain stable and low friction.

\section{Acknowledgments}

This research was conducted by the Ministry of Education, Culture, Sports, Science and Technology / Reconstruction Agency "Tohoku Innovative Materials Technology Initiatives for Reconstruction" (2012-2016). We would also like to thank SEAVAC Co., Ltd. for providing the hard coatings used in this paper.

\section{References}

[1] Manni, M. and Florio, S., "An Evaluation of Impact of Ultra Low Viscosity Engine Oils on Fuel Economy and $\mathrm{CO}_{2}$ Emissions," SAE International, 2013-01-2566, 2013.

[2] Okuyama, Y., Shimokoji, D., Sakurai, T. and Maruyama, M. "Study of Low-Viscosity Engine Oil on Fuel Economy and Engine Reliability," SAE International, 2011-01-1247, 2011.

[3] Barbezat, G., "Advanced Thermal Spray Technology and Coating for Lightweight Engine Blocks for Automotive Industry," Surface \& Coatings Technology, 200, 2005, 1990-1993.

[4] Bobzin, K., Ernst, F., Richardt, K., Schlaefer, T., Verpoort, C. and Flores, G., "Thermal Spraying of Cylinder Bores with the Plasma Transferred Wire Arc process," Surface \& Coatings Technology, 202, 2008, 4438-4443.

[5] Yamamoto, Y. et al., "Frictional Characteristics of Molybdenum Dithiophosphates," Wear, 112, 1986, 79-87.

[6] Graham, J., Spikes, H. and Korcek, S., "The Friction Reducing Properties of Molybdenum Dialkyl Dithiocarbamate Additives: Part I -Factors Influencing Friction Reduction," Tribology Transactions, 44, 4, 2001, 626-636.

[7] Graham, J., Spikes, H. and Jensen, R., "The Friction Reducing Properties of Molybdenum Dialkyl Dithiocarbamate Additives: Part II -Durability of Friction Reducing Capability," Tribology Transactions, 44, 4, 2001, 637-647.

[8] De Barros, M. I., Bouchet, J., Raoult, I., Le Mogne, Th., Martin, J. M., Kasrai, M. and Yamada, Y., "Friction Reduction by Metal Sulfides in Boundary Lubrication Studied by XPS and XANES Analyses," Wear, 254, 9, 2003, 863-870.

[9] De Barros, M. I., Bouchet, J., Martin, J. M., Le-Mogne, T. and Vacher
B., "Boundary Lubrication Mechanisms of Carbon Coatings by MoDTC and ZDDP Additives," Tribology International, 38, 3, 2005, 257-264.

[10] Grossiord, C., Varlot, K., Martin, J. M., Le Mogne, Th., Esnouf, C. and Inoue, K., " $\mathrm{MoS}_{2}$ Single Sheet Lubrication by Molybdenum Dithiocarbamate," Tribology International, 31, 12, 1998, 737-743.

[11] Morina, A., Neville, A., Priest, M. and Green, J. H., “ZDDP and MoDTC Interactions and Their Effect on Tribological PerformanceTribofilm Characteristic and Its Evolution," Tribology Letters, 24, 3, 2006, 243-256.

[12] Khaemba, D. N., Neville, A. and Morina, A., "New Insights on the Decomposition Mechanism of Molybdenum Dialkyldithiocarbamate (MoDTC): A Raman Spectroscopic Study," Royal Society of Chemistry, 45, 6, 2016, 38637-38646.

[13] Rai, Y., Neville, A. and Morina, A., "Transient Processes of $\mathrm{MoS}_{2}$ Tribofilm Formation under Boundary Lubrication," Lubrication Science, 28, 2016, 449-471.

[14] Windom, B. C., Sawyer, W. G. and Hahn, D. W., "A Raman Spectroscopic Study of $\mathrm{MoS}_{2}$ and $\mathrm{MoO}_{3}$ : Applications to Tribological Systems," Tribology Letters, 42, 2011, 301-310.

[15] Hill, C. G. Jr. and J. H. Wilson III., "Raman Spectroscopy of Iron Molybdate Catalyst Systems: Part I Preparation of Unsupported Catalysts," Journal of Molecular Catalysis, 63, 1990, 65-94.

[16] Iizumi, M., Koetzle, T. F., Shirane, G., Chikazumi, S., Matsui, M. and Todo, S., "Structure of Magnetite $\left(\mathrm{Fe}_{3} \mathrm{O}_{4}\right)$ below the Verwey Transition Temperature," Acta Crystallographica Section, B38, 1982, 2121-2133.

[17] Browne, J. D., Liddell, P. R., Street, R. and Mills, T., "An Investigation of the Antiferromagnetic Transition of $\mathrm{CrN}$," Physical Status Solidi A, 1, 1970, 715-723.

[18] Journal of the Japanese Association for Crystal Growth, Crystal Growth Handbook, Kyoritsu Shuppan Co., Ltd., 1995, 699 (in Japanese).

[19] Kim, S. J., Marquart, T. and Franzen, H. F., "Structure Refinement for $\mathrm{Cr}_{2} \mathrm{~N}$," Journal of the Less Common Metals, 158, 1, 1990, L9-L10.

[20] Koike, R., Suzuki, A., Kurihara, K. and Adachi, K., "Effect of Metal Composition on Reactive Membrane Structure Formed by Friction between Metals in MoDTC-Contained Oil," Proceedings of the Spring 2016 Tribology Conference, 2016, A3 (in Japanese).

[21] Komaba, M., Kondo, S., Suzuki, A., Kurihara, K. and Mori, S. "The Effect of Temperature on Lubrication Property with MoDTCContaining Lubricant -Temperature Dependence of Friction Coefficient and Tribofilm Structure-," Journal of Japanese Society of Tribologists, 62, 11, 2017, 703-710 (in Japanese).

[22] Koike, R., Suzuki, A., Kurihara, K. and Adachi, K., "Formation of Nano Interface by Sliding between Hard Coatings and Metals in MoDTC Contained Oil," Journal of Japanese Society of Tribologists, 64, 8, 2019, 504-512 (in Japanese)

This paper is licensed under the Creative Commons Attribution-NonCommercial-NoDerivatives 4.0 International (CC BYNC-ND 4.0) License. This allows users to copy and distribute the paper, only upon conditions that (i) users do not copy or distribute such paper for commercial purposes, (ii) users do not change, modify or edit such paper in any way, (iii) users give appropriate credit (with a link to the formal publication through the relevant DOI (Digital Object Identifier)) and provide a link to this license, and (iv) users acknowledge and agree that users and their use of such paper are not connected with, or sponsored, endorsed, or granted official status by the Licensor (i.e. Japanese Society of Tribologists). To view this license, go to https://creativecommons.org/licenses/by-nc-nd/4.0/. Be noted that the third-party materials in this article are not included in the Creative Commons license, if indicated on the material's credit line. The users must obtain the permission of the copyright holder and use the third-party materials in accordance with the rule specified by the copyright holder. Please note that the original Japanese paper from which this translated version is produced is not licensed under the Creative Commons Attribution license but is licensed under the Copyright Guideline of the Japanese Society of Tribologists. Users who wish to reprint, reproduce or translate any parts of the original paper must follow the Guideline and obtain permission from the Society. 